\title{
USING POWDER CORED TUBULAR WIRE TECHNOLOGY TO ENHANCE ELECTRON BEAM FREEFORM FABRICATED STRUCTURES
}

\author{
Devon Gonzales ${ }^{1}$, Stephen Liu ${ }^{1}$, Marcia Domack ${ }^{2}$, Robert Hafley ${ }^{2}$ \\ ${ }^{1}$ Colorado School of Mines; 1500 Illinois St.; Golden, CO 80401, USA \\ ${ }^{2}$ NASA-Langley Research Center, AMPB; 8 W. Taylor St.; Hampton, VA 23681-2199, USA
}

Keywords: EBF ${ }^{3}$, Additive Manufacturing, Powder Cored Wire, Ti-6Al-4V, Al 6061, Composite

Builds, Grain Refinement, Epitaxy

\begin{abstract}
Electron Beam Freeform Fabrication $\left(\mathrm{EBF}^{3}\right)$ is an additive manufacturing technique, developed at NASA Langley Research Center, capable of fabricating large scale aerospace parts. Advantages of using $\mathrm{EBF}^{3}$ as opposed to conventional manufacturing methods include, decreased design-toproduct time, decreased wasted material, and the ability to adapt controls to produce geometrically complex parts with properties comparable to wrought products. However, to fully exploit the potential of the $\mathrm{EBF}^{3}$ process development of materials tailored for the process is required. Powder cored tubular wire (PCTW) technology was used to modify Ti-6Al-4V and Al 6061 feedstock to enhance alloy content, refine grain size, and create a metal matrix composite in the as-solidified structures, respectively.
\end{abstract}

\section{Introduction}

Electron Beam Freeform Fabrication is a layer-additive manufacturing process that uses a CNC controlled electron beam welder coupled with wire feedstock to methodically build parts from a base substrate [1]. The vacuum environment and the high energy density beam create favorable conditions for vaporization loss of alloying elements with higher vapor pressures than the bulk material being melted. Aluminum loss from Ti-6Al-4V and magnesium loss from Al 6061 alloys were recorded in deposits made using monolithic wires. The alloy loss was significant to the effect that deposits were no longer within industrial compositional specification. Alloying enhancements of aluminum and magnesium, respectively, made to powder cored tubular wires can be used as a cost effective way to commercialize the $\mathrm{EBF}^{3}$ process for each of the two alloy systems. Experiments were conducted to determine the necessary enrichment required from PCTWs to create as-solidified builds of Ti-6Al-4Vand Al 6061 alloys. Partial re-melting of the previous layers during additive processes creates thermal cycles and gradients throughout the build. Consequently, certain alloy systems such as Ti-6Al-4V, are susceptible to epitaxial growth [2]. Epitaxy is directional grain growth across the fusion line which leads to elongated grains in the build direction. Potential problems include decreased fatigue strength, ductility, and anisotropic mechanical properties [3]. Additions of iron-boron powder were implemented in Ti-6Al-4V builds using PCTWs to mitigate epitaxial grain growth. Although not discussed in this paper, beam modulation and focal height were studied as viable processing modifications to improve the microstructure. 
High strength, lightweight materials are highly sought after in the aerospace industry. A feasibility study was conducted to determine if $6061 / \mathrm{SiC}_{\mathrm{p}}$ metal matrix composite structures can be produced using $\mathrm{EBF}^{3}$. Commercially produced metal matrix composites are produced through casting or sintering. Further processing of this material is difficult due to the wear resistance and hardness of the material. Laser-additive manufacturing processes are not feasible for producing $6061 / \mathrm{SiC}_{\mathrm{p}}$ structures. The thermal and optical properties of the aluminum and silicon carbide lead to decomposition of the silicon carbide particles and the development of detrimental phases in the melt pool [4]. Coated and uncoated silicon carbide particulates and alloying additions were incorporated in powder cored tubular wires to produce $6061 / \mathrm{SiC}_{\mathrm{p}}$ composite structures using $\mathrm{EBF}^{3}$.

\section{Discussion}

Modified Ti-6Al-4V powder cored tubular wire was manufactured using mass balance calculations and deposited in the $\mathrm{EBF}^{3}$ system. Solid monolithic alloy Ti-6Al-4V and Ti-7Al-4V composition wires were deposited using the same parameters as the PCTW. The chemical compositions of these monolithic builds were compared with that of the PCTW. Figure 1 shows the compositions of the $\mathrm{EBF}^{3}$ builds made using Ti-6Al-4V and Ti-7Al-4V monolithic wires, and the PCTW build composition with the expected alloy loss of 0.5 wt. pct. during the $\mathrm{EBF}^{3}$ process [5]. The target composition was achieved using both the Ti-7Al-4V and PCTWs, however the standard deviation was greater for the PCTW. It is expected that optimization of the PCTW fabrication process and $\mathrm{EBF}^{3}$ build parameters should result in standard deviations comparable to the alloy Ti-7Al-4V wires at a lower cost of production. Thus, this comparison shows PCTWs are a viable substitution for alloy Ti-6Al-4V and Ti-7 Al-4V monolithic wires with regards to composition [5].

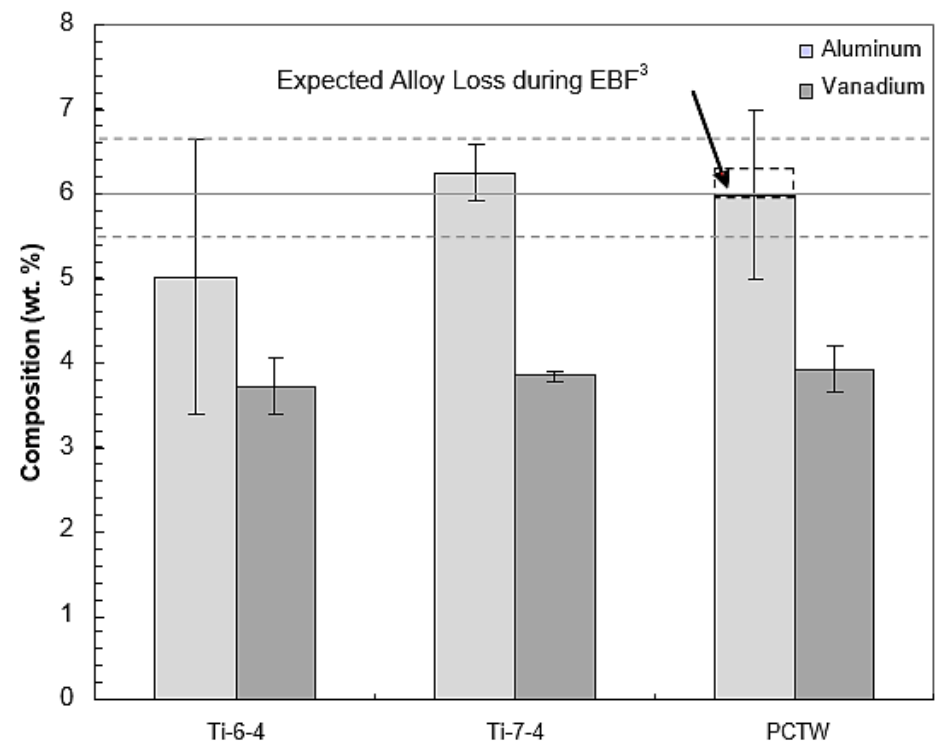

Figure 1. Comparison of post-deposition composition between monolithic and PCTWs. Solid and dashed lines are included to show the target and upper and lower chemistry tolerances, respectively, of the alloy Ti-6Al-4V [5].

Macrostructural analysis was performed comparing the PCTW build with that made using Ti7Al-4V monolithic wire. Figure 2 shows typical short transverse cross-sections of $\mathrm{EBF}^{3}$ builds 
made using PCTW and the monolithic Ti-7Al-4V wire. Both builds were composed of two preheat passes and ten deposited layers and were deposited under identical parameters of current, voltage, travel speed, and wire feed rate. The characteristic epitaxial growth of prior $\beta$ grains originating from the HAZ and extending through all layers is present in each build, as is the Widmanstätten morphology of $\alpha$ phase within the prior $\beta$ grain boundaries. Banding can also be observed from the macrographs of Figure 2, more so in the PCTW build than the monolithic wire build. Microstructures in the banding show a refinement of $\alpha$ Widmanstätten structure. Banding can also indicate the degree to which the previously deposited layer was re-melted during a pass. It is speculated that the close proximity of the banding indicates a high degree of re-melt is occurring, supporting the claim that compositional homogeneity of the $\mathrm{EBF}^{3}$ deposits is being achieved through melting and mixing of the deposited layers. Near the top of the builds, a coarser alpha structure exists, and in the heat affected zone coarse $\beta$ grains have grown from the original base plate microstructure. In addition, Vickers microhardness tests taken at the top of each deposit revealed the PCTW and monolithic builds to be of similar hardness, 314 and 312 VHN, respectively [5].

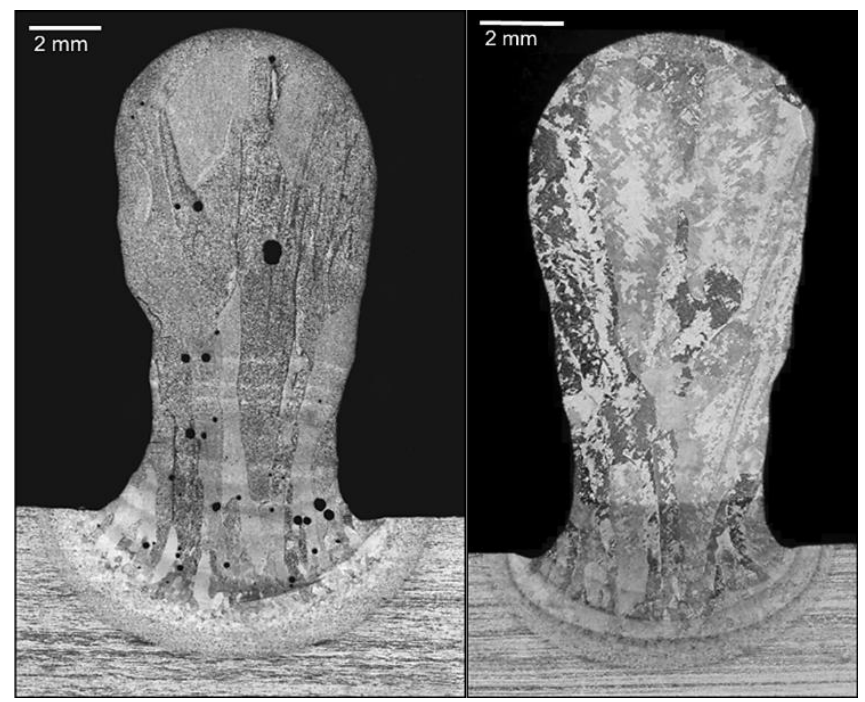

Figure 2. Short transverse cross-sections of ten-layer EBF ${ }^{3}$ deposits of (a) PCTWs, (b) Ti-7Al-4V monolithic wires [5].

Differences between the monolithic and PCTW builds arise in the high degree of porosity and both $\beta$ and $\alpha$ grain refinement in the PCTWs. The aspect ratios of $\alpha$ laths at the top of each sample were determined, as shown in Figure 3a and $\mathrm{b}$. The average length of $\alpha$ laths are comparable between the PCTW and monolithic samples, yet the width of the laths in monolithic builds are much larger than PCTW builds, resulting in aspect ratios of 20:1 in PCTW and 5:1 in monolithic builds [5]. The size of the $\beta$ grains, determined by observing the long transverse orientation of the builds, of the PCTW builds were nearly half the width of the monolithic wire builds, $500 \mu \mathrm{m}$ as opposed to $950 \mu \mathrm{m}$ [5]. 


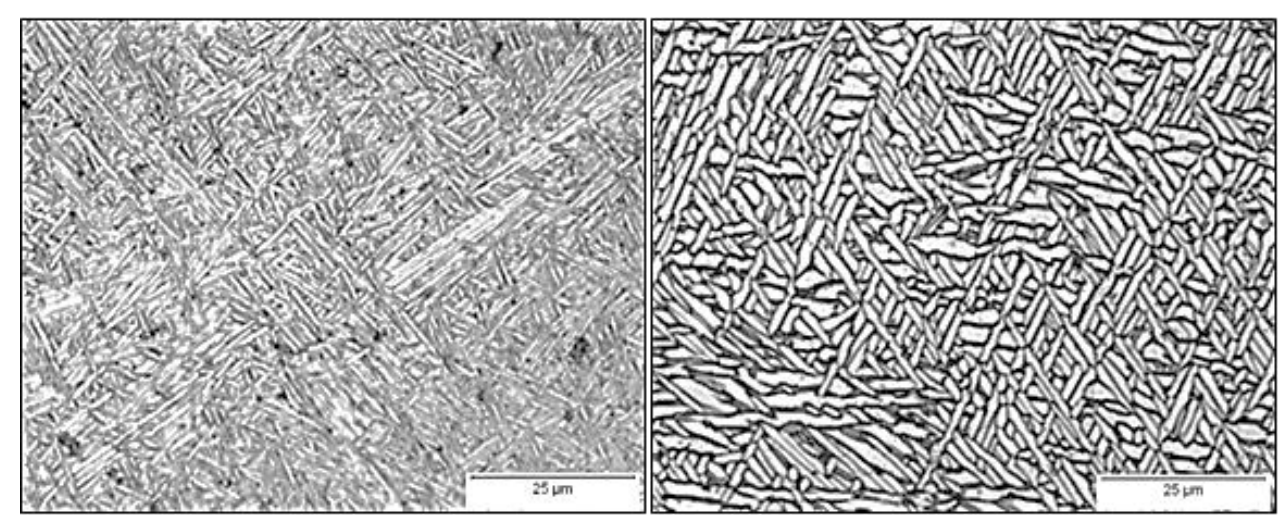

Figure 3. Comparison of $\alpha$ lath size in (a) PCTW and (b) alloyed monolithic Ti-7-4 wires showing a much finer $\alpha$ structure in PCTWs than monolithic builds [5].

Stricter procedures for the wire manufacturing process as well as optimized baking times to remove entrapped wire drawing lubricant were implemented for subsequent PCTW iterations. The PCTWs made using these modifications produced $\mathrm{EBF}^{3}$ deposits with minimal to no porosity in the as-solidified structure. However, epitaxial growth of the prior $\beta$ grains continued resulting in microstructural anisotropy in the as solidified builds. New iterations of wires were produced with the addition of the iron-boron inside a Ti-6Al-4V alloy PCTW. Cross-section macrographs of the Ti-6Al-4V and Ti-6Al-4V+FeB PCTW builds are compared in Figure 4. Large $\beta$ grain refinement due to the iron-boron addition was observed. Traditional Ti-6Al-4V alloy builds had an average $\beta$ grain size of $1450 \mu \mathrm{m}$ in Figure 4a, compared to $290 \mu \mathrm{m}$ with the iron-boron modified chemical composition in Figure 4b [3].
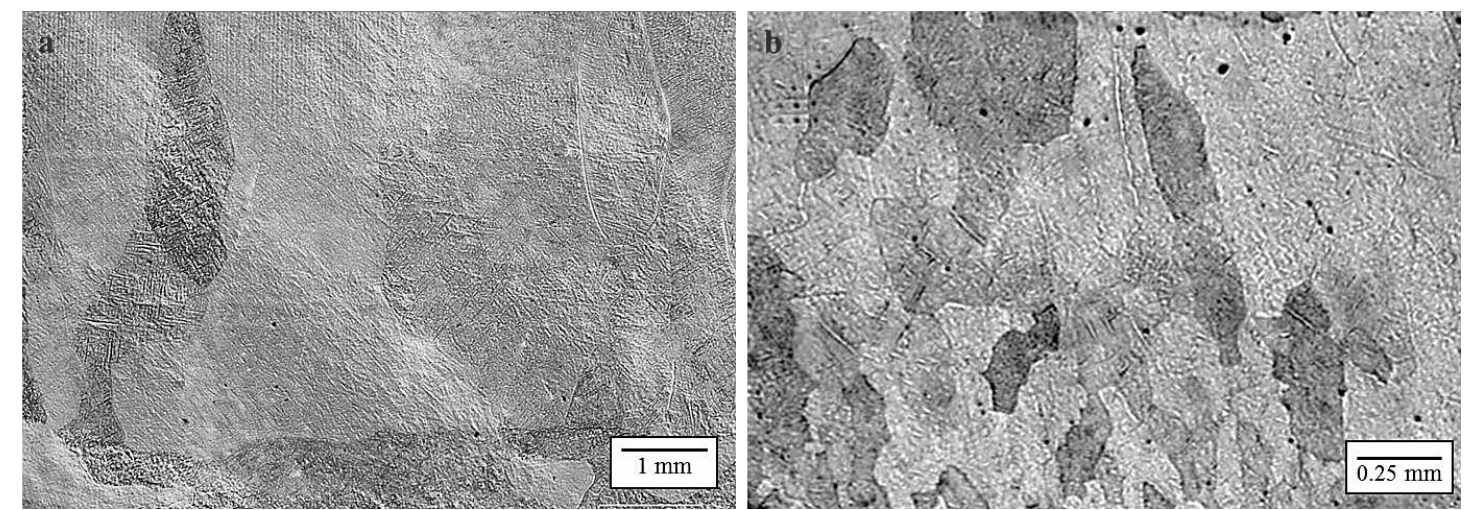

Figure 4. $\beta$ grain refinement due to iron-boron addition: (a) Traditional build macrostructure; (b) Ti-6Al-4V+FeB PCTW macrograph [3].

The formation of very fine basketweave Widmanstätten $\alpha$ laths in intermittent areas of the steady-state regions was an unexpected effect of the boron modification. The two types of $\alpha$ lath morphologies are shown in Figure 5 and reflect a refinement of $\alpha$ colony intercept length from 3.1 to $2.0 \mu \mathrm{m}$. The $\alpha$ width decreased from $0.75 \mu \mathrm{m}$, in a traditional Ti-6Al-4V build, to $0.44 \mu \mathrm{m}$ in the boron modified build [3]. Improved nucleation on intragranular boride particles is thought to be the reason for the large $\alpha$ phase refinement observed, as the increased nucleation sites caused a more competitive lath growing environment. The addition of the FeB powder refined the overall microstructure. Iron additions stabilized the $\beta$ phase while boron additions created TiB precipitates which acted as pinning points at the grain boundaries and created nucleation 
sites for new $\beta$ grains, interrupting epitaxial growth [3]. The versatility of the PCTW technology allowed for chemical and microstructural improvements to be made to Ti-6Al-4V builds using the $\mathrm{EBF}^{3}$ system.
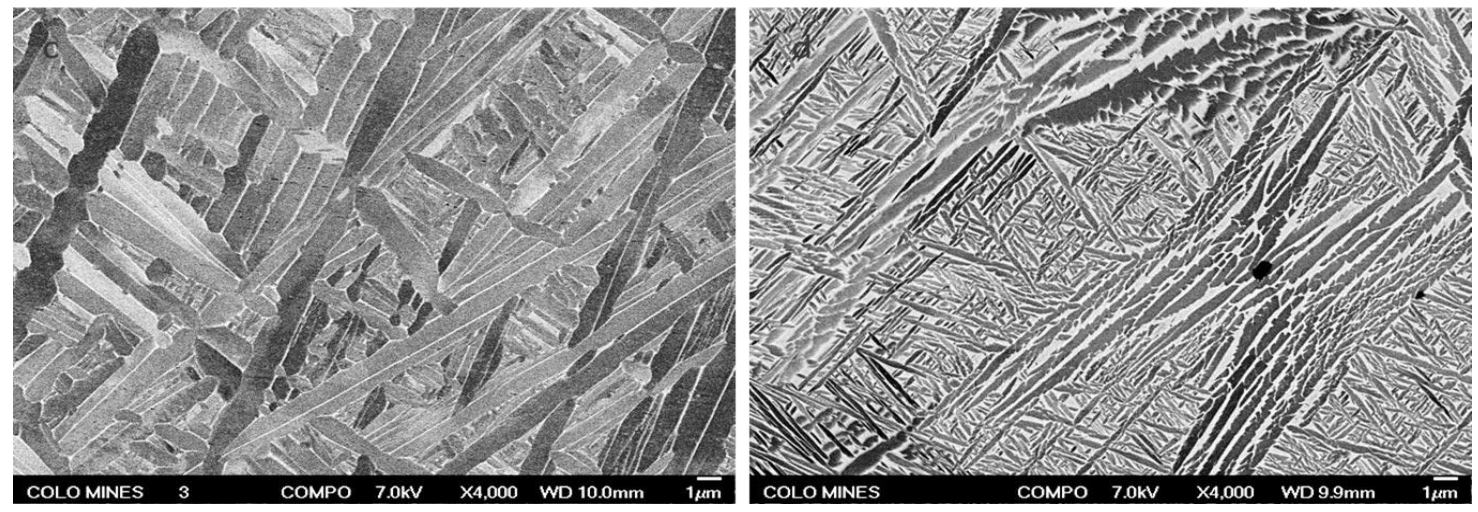

Figure 5. $\alpha$-lath refinement of Ti-6Al-4V using FeB addition. (a) Ti-6Al-4V micrograph at magnification 4000x (b) Ti-6Al-4V+FeB micrograph at magnification 4000x [3].

Principles used to create modified Ti-6Al-4V powder cored tubular wires for the $\mathrm{EBF}^{3}$ system were also applied to other alloy systems. For example, magnesium loss when depositing Al 6061 poses similar issues seen from aluminum loss in Ti-6Al-4V deposits. Modified Al 6061 PCTWs were developed to accommodate this loss. Studies were then conducted to determine the feasibility of creating a metal matrix composite as-solidified structure using PCTWs in the $\mathrm{EBF}^{3}$ system. Al 6061 alloy was used as the matrix and SiC particulates, uncoated or coated with varying thicknesses of copper and nickel, were used as reinforcements. Coatings were used to compare the degree of protection from aluminum carbide formation, a detrimental reaction that occurs between aluminum and $\mathrm{SiC}$, as well as promote particle dispersion in the matrix. It was observed that deposits containing nickel coated $\mathrm{SiC}$ formed less, in some cases no, aluminum carbide. Deposits exhibited clustering of the particulates, shown in Figure 6.

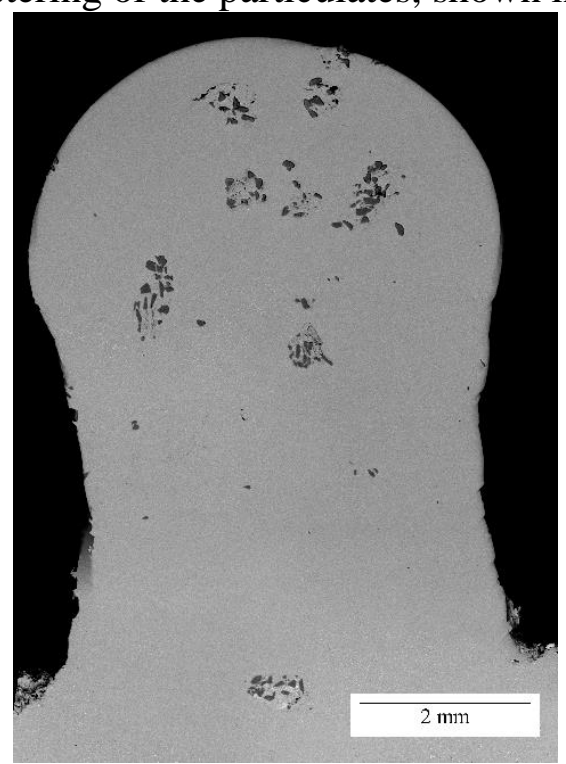

Figure 6. Macroscopic image of a ten layer deposit with low nickel coated SiC made using $\mathrm{EBF}^{3}$. 
The degree of clustering was measured and plotted in Figure 7. The cluster size (area) and mean free path (MFP) measurements were normalized by volume fraction of silicon carbide in the deposit since this can vary between different builds. Values residing in Quadrant I indicate that deposits have relatively small cluster size, a sign of increased dispersion, but a high mean free path which indicates a low volume percent of silicon carbide. The more favorable values follow the direction of the arrow in Quadrant III. These values indicate a high volume fraction of dispersed particles. Values in Quadrants II and IV indicate large amounts of agglomeration and are highly unfavorable. The data in Figure 7 indicates that low copper content (LCC), and low nickel content (LNC) coated conditions provided the highest amount of dispersion in the matrix. Agglomeration of silicon carbide particles with high copper and nickel content may occur because the coating re-solidifies too rapidly after deposition trapping the particles in large clusters. This may be exacerbated by thermal gradients generated by transitions from conductive to semi-conductive material. The electrical and thermal properties of $\mathrm{SiC}$ and other ceramic reinforcements make it difficult to process using additive manufacturing, however, modifications to the matrix and the use of metallic coatings on the reinforcement particles can lead to successful deposition of metal matrix composites using $\mathrm{EBF}^{3}$.

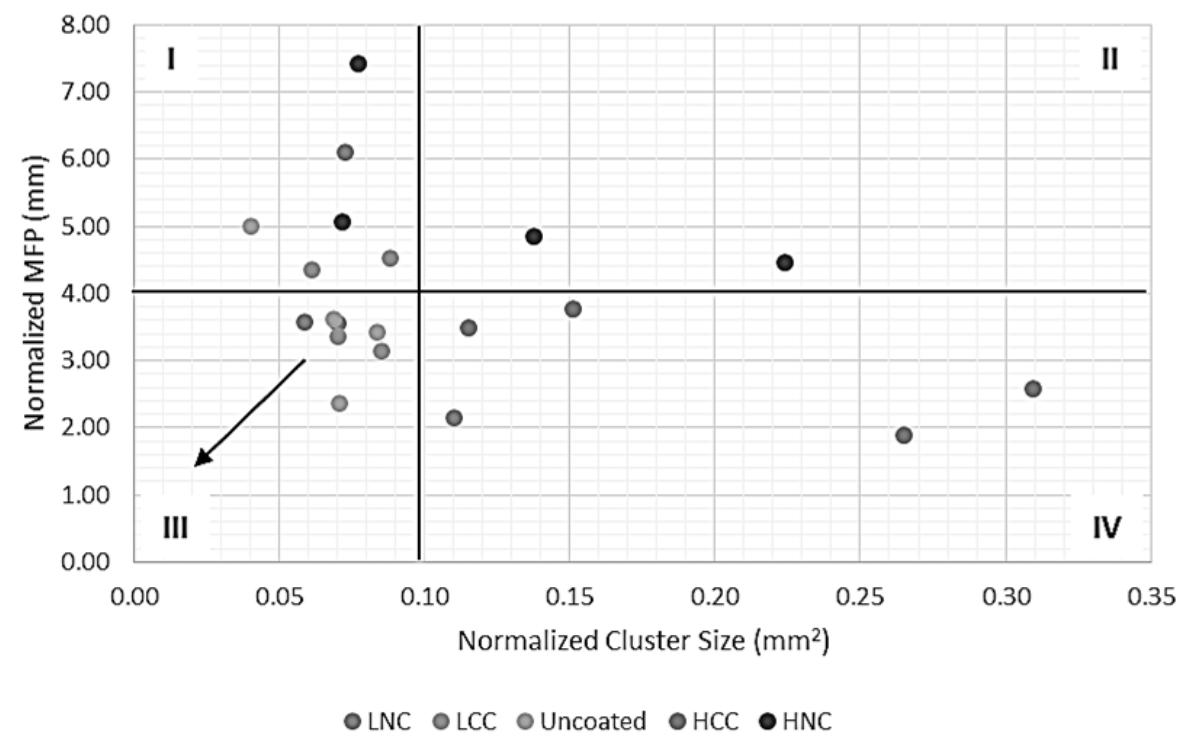

Figure 7. Plot comparing normalized mean free path and cluster size values for the five coating conditions. Highest favorability of dispersion in the direction of the arrow.

\section{Conclusions}

Powder cored tubular wire technology was used to modify the composition to produce assolidified Ti-6Al-4V deposits using the $\mathrm{EBF}^{3}$ additive manufacturing process. Powder cored tubular wires successfully replenished aluminum loss in $\mathrm{EBF}^{3}$ deposits. The deposits made using PCTWs were comparable in size and hardness to that of deposits made using commercially produced monolithic wire at a lower cost of production. Strict quality control implemented during the wire manufacturing process minimized porosity previously observed in deposits made using PCTWs. Iron-boron enhancements to the powder core significantly refined the $\alpha$-lath structure and broke up epitaxial growth of the prior $\beta$ grains in multiple layer $\mathrm{EBF}^{3}$ deposits of Ti-6Al-4V alloy. PCTW principles were applied to the Al 6061 alloy to replenish magnesium 
vaporization loss in $\mathrm{EBF}^{3}$ deposits. Further steps were taken to develop metal matrix composite powder cored tubular wires for use in the $\mathrm{EBF}^{3}$ system. It was determined that nickel coating on the silicon carbide, in optimal thicknesses, can protect the particles during deposition and enhance particle dispersion in the matrix. Results found were used as first steps for developing a commercial metal matrix composite using the Electron Beam Freeform Fabrication system.

\section{References}

1. K.M.B. Taminger and R. A. Hafley, "Electron beam freeform fabrication: a rapid metal deposition process," Proceedings of the 3rd Annual Automotive Composites Conference, Society of Plastics Engineers, Sept. 9-10, Troy, Michigan, 2003.

2. M. Karen and M. T. Robert, "Electron Beam Freeform Fabrication for Cost Effective Near-Net Shape Manufacturing.” (NATO Unclassified Report).

3. Mitzner, S. V., "Grain Refinement and Epitaxial Interruption of Freeform Fabricated Ti-6Al4V Alloy" (M.S. thesis, Colorado School of Mines, 2012).

4. T.J. Lienert, E.D. Brandon, J.C. Lippold, "Laser and Electron Beam Welding of $\mathrm{SiC}_{\mathrm{p}}$ Reinforced Aluminum A-356 Metal Matrix Composite,” Scripta Metallurgica, 28 (1993), 1341-1346.

5. Hillier, C. K., "Powder-cored Tubular Wire Development for Electron Beam Freeform Fabrication" (M.S. thesis Colorado School of Mines, 2010). 